\title{
Meningkatkan Kesejahteraan Masyarakat Nelayan Di Era New Realiti Melalui Model Pembiayaan Inklusif: Prespektif Al Mudharobah
}

\author{
Sriyono Sriyono ${ }^{1 *}$, Santi Rahma Dewi ${ }^{2)}$, Puspita Handayani ${ }^{3)}$ \\ ${ }^{1,2,3}$ Fakultas Bisnis, Hukum, dan Ilmu Sosial Universitas Muhammadiyah Sidoarjo \\ *Email korespondensi: sriyono@umsida.ac.id
}

\begin{abstract}
Kehidupan para nelayan memiliki kesejahteraan yang sangat kurang, hal ini disebaban karena pendapatan yang diperoleh sangat kecil. Penelitian tingkat kesejahteraan nelyan kupang sangat penting dilakukan dalam rangka untuk pemerataan kesejahteran msyarakat. Tujuan dalam penelitian ini adalah bagaimna cara meningkatkan kesejahteraan nelayan kupang yang berda di Kabupaten Sidoarjo. Metode penelitian yang digunakan adalah kualitatif, melalui metode ini dapat di ketahui secara mendalam dan jelas masalah yang dihadapi oleh para nelayan dalam rangkan untuk meningkatkan kesejahteraan mereka. Informan kunci dalam penelitian ini adalah msyarakat nelayan yang ada di 6 kecamatan di Kabupaten Sidoarjo, yang akan diwakili oleh 6 (satu) orang sesuai dengan jumlah lokasi di 6 Kecamatan di kabupaten Sidoarjo. Penentuan dari informan kunci ini menggunakan informan utama dan informan penunjang. Berdasarkan hasil wawancara yang dilakukan secara mendalam dan beberapa studi literatur maka ditemukan bahwa selain kurangnya modal untuk mengembangkan usaha laian juga masalah skill yang dimiliki oleh para nelayan sangat kurang sehingga mereka tidak mampu untuk melakukan usaha lain.
\end{abstract}

Kata kunci: Kesejahteraan, pembiayaan inklusif, Al Mudharobah, Era New Reality

Saran sitasi: Sriyono, S., Dewi, S. R., \& Handayani, P. (2021). Meningkatkan Kesejahteraan Masyarakat Nelayan Di Era New Realiti Melalui Model Pembiayaan Inklusif: Prespektif Al Mudharobah. Jurnal Ilmiah Ekonomi Islam, 7(01), 81-89. doi: http://dx.doi.org/10.29040/jiei.v7i1.1697

DOI: $\underline{\text { http://dx.doi.org/10.29040/jiei.v7i1.1697 }}$

\section{PENDAHULUAN}

Tingkat kesejahteraan masyarakat mencerminkan kualitas hidup dari sebuah keluarga meningkat karena kesejahteraan masyarakat merupakan hakikat dari sebuah pembangunan (Putri, 2016). Keluarga dengan tingkat kesejahteraan yang lebih tinggi berarti memiliki kualitas hidup yang lebih baik, sehingga pada akhirnya keluarga tersebut mampu untuk menciptakan kondisi yang lebih baik untuk bisa meningkatkan kesejahteraan mereka. (Prabawa, S., 1998)

Masyarakat nelayan memiliki karakteristik hidup yang beda karena pola kehidupannya yang terbentuk dari kehidupan di lautan yang tidak pernah dihadapi oleh masyarakat lain dimana mempunyai resiko yang besar, terutama resiko yang berasal dari faktor alam untuk itu perlu startegi khusus untuk bekerjanya (Rahim, A, 2018). Selain factor alam fasilitas yang dimiliki oleh para nelayan yang sangat minim yang menyebabkan kesulitan untuk memperoleh hasil tangkapan ikan. Kondisi seperti ini yang mengakibatkan nelayan menjadi kurang sejahtera (Kusnadi, 2015), oleh karena itu kondisi dari kesejateraan nelayan tergantung dari kondisi pesisir tersebut (Limi, 2017, Sugiharto, 2017)

Kesulitan untuk meningkatkan kesejahteraan nelayan tradisional dipengaruhi oleh sejumlah faktor yaitu keterbatasan kualitas sumberdaya manusia, keterbatasan kemampuan modal usaha dan informasi teknologi penangkapan (Takariani, C.S.D. 2015.), kesulitan melakukan deversifikasi usaha penangkapan selain itu juga sistem hasil pemasaran hasil perikanan yang lebih menguntungkan pedagang perantara (Mulyadi, 2005). Ditambah lagi adanya pandemic Covid 19 menimbulkan dampak yang cukup besar, munculnya kebijakan-kebijakan yang diberlakukannya sebagai upaya untuk mengurangi penyebaran Covid termasyarat. 


\section{Jurnal Ilmiah Ekonomi Islam, 7(01), 2021, 82}

Berdasarkan pengawatan awal, fakta dilapangan menyebutkan bahwa pemberdayaan masyarakat nelayan yang hidup disana mempunyai taraf hidup jauh dari kata sejahtera (Suyanto, 2009). Pendapatan yang diperoleh dari hasil nelayan jauh dari harapan, sehingga diperlukan pembiayaan untuk mengatasi masalah utama yang sedang dihadapi saat ini. Banyak sekali tawaran pembiayaan namun demikian sebagian besar memerlukan syarat dan system yang tidak bisa dipenuhi oleh masyarakat nelayan (Gizaw, 2015). Selain itu dari pihak perbankan juga mempunyai kekwatrrian terhadap resiko gagal bayar mengingat bahwa pendapatan yang diperoleh oleh nelayan tidak pasti (Ogboi, 2013)

Agar kehidupan eknomi nelayan meningkat maka perlu dibantu peningkatan akses masyarakat terhadap kelembagaan ekonomi, mengoptimalkan kelembagaan masyarakat ke dalam setiap program Pemerintah, mengintegrasikan kelembagaan informal dengan kelembagaan formal (Rostin. 2016.), serta mengaktifkan koperasi nelayan yang sudah ada ada mendirikan koperasi baru dengan sumber daya manusia pengelola yang professional (Triyanti dan Firdaus, 2016)

Melalui model pembiayaan inklusif dengan system Al Mudharobah diharapkan antara para nelayan dan pemberi modal terhindar dari system riba yang di haramkan bagi umat islam seperti tercantum dalam Surat Al Baqoro ayat 276.

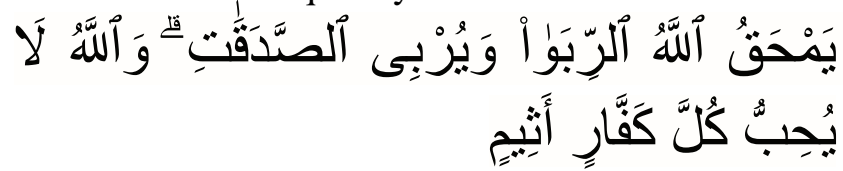

Melalui pembiayaan ini diharapkan dapat membuka peluang usaha tambahan baru atau untuk meningkatkan system pemasaran digital atau mengganti/menambah peralatan yang dimiliki saat ini. Inklusi keuangan merupaka tema penting yang dibahas dalam dalam agenda global. saat ini telah menjadi agenda global. Fair Finance Guide International (FFGI) mengedepankan tema mendorong keuangan berkelanjutan dalam praktek bisnis perbankan.

Sebagai Lembaga keuangan yang mendukung pengembangan ekonomi yang berkelanjutan maka Bank mempunyai kewajiban untuk memenuhi kebutuhan masyarakat tersebut melalui produkproduk yang dimilikinya. Melalui produk-produk tersebut salah satu diantaranya adalah memberikan kredit pinjaman, bank dapat menolong perusahaan dan pemerintah untuk menjalankan peran dan bisnisnya, serta memampukan pengembangan inovasi produk dan solusi yang dapat menyelesaikan lapisan persoalan sosial dan krisis lingkungan yang dihadapi. Dengan menyediakan pinjaman dan merangsang investasi produktif, bank dapat mengambil peran kunci dari setiap kegiatan bisnis yang ada (Nugroho, Lucky dan Dewi Tamala, 2018)

Kabupaten Sidoarjo memilili 6 Kecamatan pesisir dari 18 kecamatan yang ada. Keenam kecamatan tersebut terbagi menjadi 20 desa pesisir yang mepunyai potensi laut yang besar. Sidoarjo memiliki potensi laut yang baik karena secara geografis kabupaten ini memiliki wilayah pesisir yang masuk di kawasan pesisir utara Jawa Timur. Pengelolaan dan sumberdaya manusia adalah hal yang menjadi halangan dalam pengambilan sumberdaya laut sebagai tulang punggung kehidupan. (Tjahyono, Dkk., 2018)

Masyarakat nelayan di beberapa Kecamatan di Kabupataen Sidoarjo sebagian besar mayoritas merupakan nelayan tradisional dan menggunakan kapal yang masih sederhana. Kondisi ini yang menyebabkan nelayan yang berada di Kabupaten Sidoarjo sangat tergantung dengan kondisi cuaca. Karena ketergantungan tersebut bila tidak bisa mengambil kupang maka mereka akan tidak mendapat penghasilan sehingga mereka terpaksa harus berhutang untuk memenuhi kebutuhan hidu. Orang terdekat yang dapat mempercayai mereka yaitu para pengepul, mereka terpaksa harus berutang kepada mereka untuk pemenuhan kebutuhan hidup dengan perjanjian yang dapat memberatkan nelayan

Penelitian ini bertujuan untuk meningkatkan kesejahteraan masyarakat nelayan yang berada di Kabupaten Sidoarjo pasca Covid 19 melalui Model Pembiayaan inklusif dengan perspektif AlMudharobah. Melalui penelitian ini diharapkan memberika jalan keluar masalah yang sedang dihadapi saat ini untuk meningkatkan kesejahteraan masrayat nelayan yang berada di pesisir Kabupaten Sidoarjo.

\section{METODE PENELITIAN}

Penelitian ini menggunakan pendekatan kualitatif (Cresswell et al. 2007), dengan menggunakan pendekatan interpretif (Lukkaa, K., dan S. Modell, 2010) pendekatan ini sangat sesuai karena penelitian ini mengintepretasikan hasil in depth interview dengan informan kunci. dan eberikan rincian yang oplek tentang fenomena keejahteraan yang sulit 
diungkap dengan metode kuantitatif ( Staruss dan Corbin, 2003)

Pada penelitian ini fokus untuk menggali informasi, memahami dan menganalisa pendapat informan atas kesejahteraan, pembiayaan inklusi dan perspektif Al Mudharoba. Kesejahteraan dalam penelitian ini apakah masyarakat nelayan tingkat kesejahteraannya sudah sesuai dengan standard yang telah dibentuk. Unit analisis penelitian ini adalah para informan kunci yang terdiri dari beberapa masyarakat nelayan yang diwakili oleh 6 (enam) oarng disetiap kecamatan serta para pengamat social tentang kesejahteraan nelayan dan para pakar ahli bidang kesejahteraan dan pakar pembiayaan inklusif (Marshall, 1996)

Informan kunci dalam penelitian ini adalah msyarakat nelayan yang ada di 6 kecamatan di Kabupaten Sidoarjo, yang akan diwakili oleh 6 (satu) orang sesuai dengan jumlah lokasi di 6 Kecamatan di kabupaten Sidoarjo. Penentuan dari informan kunci ini menggunakan informan utama dan informan penunjang. Penentuan inform ini dilakukan dengan jddgement untuk Beberapa tahapan yang dilakukan dalam penelitian ini adalah : In Depth Interview (Moleong, 1996), dokumentasi, Observasi. Uji keabsahan data penelitian ini dilakukan dengan beberapa tahapan yaitu credibility dan transferability (Senton, 2004). Credibility dilakukan dengan cara triangulasi sumber dan triangulasi metode (Hussien, 2009). Transferability dilakukan dengan cara membuat laporan hasil penelitian secara terinci, sistematis, dan dapat dipercaya.

Ada tiga alur kegiatan yang terjadi secara bersama, yaitu: Reduksi data (reduction data), penelitian (data lapangan) menyajikan data (data display), yakni memudahkan bagi peneliti untuk melihat gambaran secara keseluruhan atau bagianbagian tertentu dari penelitian. Menarik kesimpulan (conclusiondrawing), yakni sejak awal memasuki lokasi penelitian dan selama proses pengumpulan data. Peneliti berusaha untuk menganalisis data yang dikumpulkan dengan cara mencari pola, tema, hubungan persamaan, hal-hal sering timbul dan sebagainya yang dituangkan dalam kesimpulan.

\section{HASIL DAN PEMBAHASAN}

\subsection{Hasil Penelitian}

Hasil dari penelitian ini didasarkan pada analisis data yang diperoleh dari indeth interview, data sekunder, dan pendokumentasian yang dilakukan.
Keabsahan data dengan menggunakan yrtriangulasi dan reduksi dengan coding yang dilakukan oleh peneliti yang bertindak sebagai intrumen penelitian yang punya kemampuan untuk mnyeleksi data-data yang menjadi konsep dari penelitian ini.

Tabel 1. Coding dan Konsep Penelitian

\begin{tabular}{|c|l|l|}
\hline Coding & Konsep Penelitian & Indepth Interview \\
\hline A. & Aktivitas Nelayan & $\begin{array}{l}\text { Jenis pekerjaan } \\
\text { nelayan }\end{array}$ \\
\hline B & Kesejahteraan & $\begin{array}{l}\text { Kesejahteraan } \\
\text { keluarga }\end{array}$ \\
\hline C & Inovasi Nelayan & Diversifikasi Produk \\
\hline D & Peran Pemerintah & Bantuan perahu \\
\hline E & $\begin{array}{l}\text { Peran lembaga } \\
\text { keuangan }\end{array}$ & $\begin{array}{l}\text { Pembiayaan dari } \\
\text { perbankan }\end{array}$ \\
\hline
\end{tabular}

\section{a. Aktivitas Nelayan}

Berdasarkan hasil coding konsep maka mamawancara awal ditanyakan pada nelayan yang ada di sungai kedungpeluk, yaitu tujuan terakhir yang digunakan untuk menurunkan hasil tangkapan di laut. Wawancara kami lakukan pertama kepada Bpk Nuralim, assalammualaikum Pak, lagi nunggu kapal dari laut ya pak?, jawaban yang kami peroleh:

waalaikumsalam, oh iya pak lagi nunggu kapal yang membawan kupang dari laut?, pertanyaan berikutnya adalah, apakah bapak termasuk nelayan kupang pak ?, oh bukan, jawaban dari dia. Saya bukan nelayan pak? jadi bapak sebagai apa ? begitu pertanyaan berikutnya. Jawaban yang diperolah adalah: begini pak, disini ini ada tiga kelompok yaitu nelayan, pengepul dan pengelola atau produsen kerrang. Saya disini sebagai pengepul yang mempunyai beberapa nelayan. Jadi saya tinggal order saja ke para nelayan untuk kebutuhan kerrang tersebut, kalau kerrang banyak saya tinggal bilang supaya ambil banayk tapi kalau pasar sepi maka saya tinggal bilang supaya diambilkan sedikit di laut.

oh begitu pak, jadi bapak sebagai pengepul, terus sebagai pengelola atau produsen siapa ? d atau dengan kata lain setelah Bapak kumpulkan kupang tersebut Bapk jul kemana ?, jawabnya adalah: 
setelah saya kumpulkan kupang dari nelayan yang tidak saya jual kemana-mana legi karena saya masak sendiri, jadi saya sebagai pengepul dan pengelola kupang. Setelh kupang matang maka baru kupang saya jual ke pasar atau ada orang yang langsung ambil dirumah.

oh begitu ya pak !!, jadi bapak sebagai pengepul kupang sekaligus yang masak dan menjual ke pasar melalui pedagang ?, jawabnya benar pak begitu?

Berdasarkan hasil wawancara diperolah gambaran bahwa nelayan kupang tidak bisa berdiri sendiri, ini menunjukkan bahwa proses perdagangan makanan kupang mempunyai rantai penjualan yang cukup banyak. Hal ini menunjukkan biaya yang dierlukan untuk memasak kupang untuk siap dijual ke pembeli utama (end user) memerlukan beberapa macam distribusi mulai dari laut sampai pembeli

Adanya rantai distribusi ini menunjukkan bahw harga jual yang sampai ke pembeli tidak sama dengan harga jual dari petani kupang karena penjualan kupang masi melalui beberapa tahapan, semakin Panjang tahapan ini maka harga jual kupang ke pembeli akhir akan jadi semakin mahal. Ini juga berarti nelayan kupang tidak dapat menikmati untung yang tinggi miskipun harga jual di pembeli tinggi karena kupang yang berasal dari nelayan kupang tidak langsung bisa di beli oleh pemakaia tapi masih mengalami pemrosesan lagi.

\section{b. Kesejahteraan Nelayan}

Kemudian pertanyaan kami ajukan kepada nelayan kupang langsung tentang kegiatannya sehari-hari, bapak bekerjanya muai jam berapa tiap hari dan selesainya jam berapa?, jawaban yang saya peroleh adalah:

biasanya kami persiapan berangkat mulai jam 01.00 - 02.00, menyiapkan seтиa keperluan selama dilaut kemudian kami berangkat jam 03.00. Kami biasanya 7-10 orang setiap perahu, tergantung perahunya. Setelah kami selesai mengambilkupang maka kami mulai merapat ke lokasi penurunan kupang di sungai. Biasa kami sampai lokasi sekitar kam 13.00 sampai 14.00 itu juga tergantung kondisi di lautnya, tapi rata rata jam itu.
Jadi bapak mengambilnya rata-rata berapa kg kupang pak?:

sebenarnya tidak mesti, satu perahu muat untuk 8 sampai 10 orang. 1 perahu bisa mengangkut \pm 100 karung kupang, 1 karung dengan berat 18 sampai $20 \mathrm{~kg}, 1$ karung dijual dengan harga Rp16.000., disamping itu tergantung sama pengepul kupang juga kalau kupangnya laris seperti sebelum ada korona ya banyak pak, tapi sejak ada korona pesanan kupang juga turun sekitar 25-30\%. Jadi saya tidak bisa menentukan sendiri karena saya tidak ikut jualan kupang.

kemudian kami lakukan triangulasi sumber dan diperoleh jawaban yang sama dari tiap nelayan kupang, setiap kelompok mempunyai anggota yang berbeda-beda, tergantung dari besarnya perahu yang dimilki.

Setiap kelompok bekerja sendiri-sendiri dan juga mempunyai pengepul kupang langganan, ada beberapa pengepul kupang untuk melayani para nelayan kupan, sedang perahunya dimiliki oleh seseorang yang bukan bagian dari pengambil kupang atau nelayan kupang. Ada beberapa macam perahu yang dipakai, ada perahu yang dimiliki oleh perorangan sehingga modelnya sewa perorang dengan tarif Rp 10.000 - Rp 20.000 per orang

Melihat kondisi tersebut maka nelayan kupang memperoleh pendapatan hanya sedikit karena nelayan menjual hasil kupang mentah saja dengan harga yang murah kepada pengepul kupang. Maka keuntungan dari pengambilan kupang sangat sedikit bila dibandingkan dengan pendapatan pengelolan kupang karena memasak kupang dan langsung bisa melakukan negoisasi dengan pembeli. Ini menunjukkan bahwa adanya proses distibusi yang menyebabkan bahwa harga barang akan menjadi lebih mahal.

\section{c. Inovasi}

Pertanyaan beikutnya yang kami tanyakan adalah, apakah bapak mempunyai kegiatan lain atau punya keahlian lain selain mengambil kupang?, jawaban yang kami peroleh adalah:

pekerjaan kami hanya nelayan mengambil kupang saja, bila kami balik ke pasuruan maka pekerjaan kami hanya sebagai buruh tania tau membantu serabutan pak, jadi hanya itu yang kami bisa lakukan. 


\section{Jurnal Ilmiah Ekonomi Islam, 7(01), 2021, 85}

Kondisi nelayan tersebut menyebabkan kesejahteraan nelayan menjadi kurang, karena pekerjaannya hanya menjadi nelayan kupang. Untuk itu perlu dilakukan pengembangan keahlian dan bantuan pembiayaan yang tidk memerlukan syarat berat dan dengan proses yang mudah serta pengembaliannya yang tidak memberatkan. Melalui bantuan pembiayan tersebut nelayan kupan diharapkan bisa melakukan usaha lain atau menjadi pengepul atau pengelola kupang langsung.

Untuk proses pembiayaan seperti tersebut diatas maka model pembiayaannya yang sesuai adalah Model Pembiayaan Inklusif $\mathrm{Al}$ Mudharobah, model ini adalah model pembiayaan yang di lakukan dengan pendampingan dan sistemnya adalah hasil keuntungan dari penggunaan dana tersebut dibagi bersama berdasarkan nisbah yang disepakati. Untuk system pengembaliannya ditentukan dengan kesepakatan yang telah disetujui antara pemberi kedua belah pihak yakni shahibul maal (pemilik dana) dan mudharib (pengelola).

\section{d. Peran Pemerintah}

Selain itu kami tanyakan juga tentang peran pemerintah terhadap kesejahteraan, pertanyaan yang kami ajukan adalah. Apakah pemerintah pernah melakukan bantuan terhadap kegiatan nelaya ?, jawaban yang kami perolah sebagai berikut:

pernah membantu Pak, pemerintah kabupaten membantu kami dalam bentuk peralatan yang kami gunakan yaitu perahu dan perlengkapannya. Perahu tersebut dikelola oleh kelompok nelayan dan kami gunakan secara bergantian untuk mencari kupang

Apakah pernah dilakukan bantuan tentang pembiayaan? jawaban mereka adalah:

sampai saat ini belum pernah dilakukan pembiayaan pada nelayan perorangan, karena kami semua adalah bukan penduduk sidoarjo. Untuk nelayan kupang yang berada di daerah sidoarjo mungkin bantuan melalui kelompok nelayan.

Apakah pernah di lakukan pembentukan koperasi nelayan kupang? jawaban mereka:

pernah kami ditawari untuk membentuk koperasi, tapi kami yang nelayan khan bukan penduduk sidoarjo jadi mungkin ada kesulitan, seperti diketahui yang menjadi nelayan kupang Sebagian besar adalah pendatang dari Pasuruan

Kemudian pertanyaan tersebut kami lakukan triangulasi sumber dengan para pengepul sekaligus pengolah kupang tentang penbentukan koperasi, jawaban yang kami terima adalah:

ya Pak memang kami pernah mencoba untuk membuat koperasi khusus nelayan tapi kami mengalami banyak kendala selain para nelayan bukan penduduk sidoarjo kami juga mengalami kesulitan untuk koordinasi dengan mereka, khususnya mengenai pembayaran iuran wajib dan iuran pokok dianggap memberatkan mereka.

\section{e. Peran Lembaga Keuangan}

Untuk kepentingan pembiayaan tersebut, kami melakukan wawancra dengan salah satu Lembaga keuangan non perbankan yang dapat memberikan pembiayaan model inklusi jenis AL Mudharobah yaitu LAZISMU. Pertenyaan kami ajukan kepada kepala LAZISMU yang berda di Kabupaten Sidoarjo, pertanyaan yang kami ajukan adalah apakah pihak LAZIZMU dapat memberikan pembiayaan pada UMKM?, jawaban yang kami peroleh adalah:

kami adalah Lembaga keuangan non perbankan yang membantu kaum duafa khususnya, namun demikian kami juga dapat memberikan kepada masyarakat yang mempunyai kegiatan usaha yang memerlukn bntuan.

Pertanyaan berikut yang kami tanyakan adalah, apakah dalam bantuan pembiayaan tersebut memerlukan persyaratan khusus ?, jawaban yang kami peroleh adalah:

Lembaga kami adalah Lembaga yang memberikan bantuan secara Cuma-Cuma kepada kaum dhuafa, namun demikian kami juga dapat memberikan kepada masyarakat lain yang epunyai usaha tanpa persyaratan apapun, tapi besarnya yang bisa kami berikan ada batasannya karena kami berikan dengan model hibah.

apakah ini berarti bahwa LAZISMU juga dapat memberikan kepada para nelayan kupang agar dapat meningkatkan kesejahteraan dengan membuka usaha baru?, jawannya adalah: 


\section{Jurnal Ilmiah Ekonomi Islam, 7(01), 2021, 86}

kami dapat memberikan bantuan secara hibah maupun dengan model yang telah disepakati kepada masyarakat secara luas setelah kami survey dan memang orang tersebut layak untuk menerima. Kami memberikan pembiyaan dengan system hibah atau system Syariah agar tidak memberatkan.

Berdasarkan hasil wawancara maka nelayan kupang mempunyai kesempatan untuk memperoleh pembiayaan baik dengan system hibah maupun dengan system Syariah. Namun demikian yang perlu dipikirkan adalah keahlian dari para nelayan sangat minim dan perlu dikembangkan. Bila diberi bantuan pembiayaan maka perlu dilakukan model pembiayaan inklusi sehingga dapat diarahkan begaimana cara menggunakan dana tersebut

\subsection{Pembahasan}

Kebijakan pembangunan masyarakat pesisir pada masa yang akan datang hendaknya didasarkan pada landasan pemahaman yang benar tentang peta permasalahan pembangunan masyarakat itu sendiri, yaitu mulai dari permasalahan mikro sampai pada permasalahan di tingkat makro yang mengarah pada pemberdayaan masyarakat nelayan. Permasalahan mikro yang dimaksudkan adalah persoalan internal masyarakat nelayan menyangkut aspek sosial budaya seperti pendidikan, mentalitas, dan sebagainya, aspek ini yang mempengaruhi sifat dan karakteristik masyarakat nelayan. (Ulfa, 2017)

Sifat dan karakteristik tersebut dipengaruhi oleh jenis kegiatan usaha seperti usaha penakapan kupang, usaha perikanan tambak, dan usaha pengolahan hasil perikanan. Kelompok masyarakat ini memiliki sifat unik berkaitan dengan usaha yang dilakukannya. Karena usaha perikanan sangat bergantung pada musim, harga dan pasar maka sebagian besar karakter masyarakat pesisir (khususnya nelayan dan petani ikan) tergantung pada faktor- faktor tersebut. Oleh karena itu diperlukan strategi untuk mengatasi hal tersebut.( Helmi, Dan Satria. 2012)

Masyarakat nelayan kupang mempunyai kakteristik amat tergantung pada kondisi lingkungan atau rentan pada kerusakan khususnya pencemaran atau degradasi kualitas lingkungan, kehidupan masyarakat nelayan sangat tergantung pada musim, ketergantungan terhadap musim ini akan sangat besar dirasakan oleh nelayan-nelayan kecil. Selain itu persoalan lain dari kelompok masyarakat nelayan adalah ketergantungan terhadap pasar, hal ini disebabkan komoditas yang dihasilkan harus segera dijual untuk memenuhi kebutuhan hidup sehari-hari atau membusuk sebelum laku dijual karena berpengaruh terhadap harga. (Yaskun, Mohammad dan Edie Sugiarto, 2017)

Permasalah yang dihadapi oleh para nelayan kupang adalah tingkat kesejahteraannya yang masih rendah sehingga perlu dicarikan solusi yang dapat meningkatkan kesejahteraan nelayan tersebut. Berdasarkan hasil wawancara masalah pokok yang dihadapi adalah para nelayan tidak memiliki skill yang lain, jadi paling utama perlunya peningkatan skill agar mampu melakukan inovasi untuk meningkatkan kesejahteraannya, selain itu perlu dilakukan bantuan pembiayaan inklusi agar nelayan mampu mengembangkan usaha dan pengelolaan keuangan. (Karof, 2013)

Melalui peningkatan skill manajemen dan keahlian lainnya maka diharapkan para nelayan akan dapat melakukan inovasi usaha selain sebagai nelayan kupang. Melalui inovasi tersebut maka para nelayan dapat menambah pendapatan dan pada akhir akan dapat meningkatkan pendapatannya dan akhirnya meningkatkan kesejahteraannya (Rusliadi, 2018). Untuk memberikan pembiayaan maka akan dilakukan dengan model pembiayaan inklusi perspektif $\mathrm{Al}$ Mudharobah, mengapa hal ini dilakukan karena tingkat pengetahuan tentang manajemen keuangan dan bisnis maka nelayan perlu di lakukan edukasi dan pendampingan bagaimana cara mengelola uang tersebut.( Kara, 2013)

Adanya Peraturan Daerah Kabupaten Sidoarjo Nomor 4 Tahun 2014 pasal 44 tentang Perlindungan dan Pemberdayaan Petani/ Pembudidaya Nelayan, fasilitas pembiayaan dan permodalan dilakukan dengan pemberian pinjaman modal dan pemberian bantuan penguatan modal, bantuan kapal membantu nelayan yang sedang tertimpa musibah akan tetapi tidak dapat memenuhi semua keinginan nelayan karena mahalnya harga kapal serta anggaran yang terbatas. (Lamia, 2013). Selain itu bantuan asuransi diberikan kepada nelayan oleh Dinas Perikanan dan Jasindo senilai 200 juta bila kecelakaan dilaut, 160 juta bila meninggal dan 20 juta bila sakit. Akses permodalan yang diberikan kepada nelayan melalui bank BRI dengan jaminan berupa sertifikat rumah. Hal ini memang sangat membebankan nelayan, akan tetapi mereka harus pandai dalam mengatur keuangan 
untuk mengembalikan modal yang telah dipinjam ke bank.(Mira, 2016)

Pengelolaan keuangan yang baik dapat meminimalisir kondisi keuangan mereka yang menipis, namun hal ini sangat sulit untuk dilakukan karena tingkat pengetahuan yang rendah tentang pengelolaan keuangan. Kalaupun bantuan dan akses permodalan dari pemerintah maupun perbankan dianggap masih kurang dan sulit (Sitinjak, Ladestam dan Henry Sinaga. 2019) maka nelayan akan beralih dengan meminta pertolongan dari juragan/tengkulak. Bantuan dari juragan/tengkulak tersebut digunakan sebagai modal melaut dan juga kebutuhan sehari hari. Nelayan beranggapan bahwa tawaran yang diberikan oleh juragan/tengkulak lebih mudah dan prosesnya pun tidak rumit. Kemudahan tersebut juga memiliki resiko yang harus ditanggung nelayan dengan system bagi hasil tangkapan yang tidak merata atau sesuai harga pasaran karena dipotong sedikit untuk mencicil hutang yang mereka pinjam, kalau ini dibiarkan akan merugikan nelayan kupang.( Lubis., dkk. 2012)

Indeks inklusi keuangan global yang dibuat oleh World Bank tahun 2015 menunjukkan bahwa kurang dari separuh masyarakat Indonesia (40 persen) yang memiliki akses pada lembaga keuangan formal, lebih rendah dari pada Thailand dan Malaysia yang hampir mencapai 80 persen. Sementara survei inklusi keuangan OJK pada tahun 2013 menemukan bahwa 52 persen rumah tangga di Indonesia tidak memiliki tabungan sama sekali. Dari masyarakat yang memiliki tabungan, sebanyak 78 persen menyimpan uangnya di bank, sisanya tidak. Hal ini menunjukkan bahwa inklusifitas keuangan di Indonesia masih rendah. (OJK, 2019). Melalui model inklusi dengan perspektif Al Mudharoba maka akan memberikan kelonggaran serta beban yang ringan, sebab system yang diberikan tidak memberatkan bagi nelayan kupang dimana mereka tidak mempunyai pendapatan yang tetap dan pasti.

\section{KESIMPULAN}

Penguatan untuk meningkatan kesejahteraan nelayan kupang harus dilakukan dengan cara terintegrasi anata menambah skill nelaya dan bantuan pembiayaan yang bersifat Al Mudharobah, ini dilakukan agar para nelayan mampu melakukan inovasi dalam kegiatan sehari-harinya selain menjadi nelayan pengambil kupang juga melakukan kegiatan usaha lainnya untuk meningkatkan kesejahteraannya.
Untuk itu juga diperlukan bantuan pembiayaan jenis Al Mudharoba agar nelayan dapat merasakan bantuan pembiayaan tersebut tanpa merasa terbebani dengan kewajiban dan syarat yang komplek

\section{UCAPAN TERIMA KASIH}

Terima kasih kami ucapkan kepada Majelis Diktilitbang Muhammadiyah, serta Universitas Muhammadiyah yang telah memeberikan kesempatan untuk dapat mengikuti Hibah Risetmu Skeme Covid-19. Semoga saja hasil penelitian ini berguna untuk Universtas Muhammadiyah khususnya dan masyarakat nelayan umumnya sebagai masukan upaya untuk meningkatkan kesejahteraaan nelayan kupang di Kabupaten Sidoarjo.

\section{REFERENSI}

Bintarto. 1989. Interaksi Desa Kota dan Permasalahannya. Ghalia Indonesia. Jakarta

Creswell, John W., William E. Hanson., Vicki L Plano Clark., dan Alejandro Morales. (2007). Qualitative Research Designs: Selection and Implementation. The Counseling Psychologist. Vol 35, No 2. March. Pp 236 -264.

Fahrudin, Adi. (2012). Pengantar Kesejahteraan

Sosial. Bandung: Refika Aditama

Gizaw, Million., Matewos Kebede and Sujata Selvaraj. (2015). The Impact Of Credit Risk On Profitability Performance Of Commercial Banks In Ethiopia. African Journal Of Business Management, 9(2): Pp: 59-66.

Hussien, Ashatu. (2009). The Use of Triangulation in Social Science Research: Can Qualitative and Quantitative Methods be Combined ?. Journal of Comparative Social Work

Helmi, Dan Satria. 2012. Strategi Adaptasi Nelayan

Terhadap Perubahan Ekoligis. Jurnal: IPB. Vol 16, No. 1, Juli 2012:68-78.

Irmawati, S., D.Damelia, dan D.W.Puspita. (2013). Model Inklusi Keuangan pada UMKM Berbasis Pedesaan. Jejak, Journal of Economics and Policy 6 (2) (2013): 103-213.

Kusnadi. (2015). Pembangunan Wilayah Pesisir Terpadu: Strategi Mengatsasi Kemiskinan Nelayan. Graha Ilmu : Yogyakarta

Karof Alfentino Lamia, Karof Alfentino 2013. FaktorFaktor Yang Mempengaruhi Tingkat Pendapatan Nelayan Kecamatan Tumpaan, Kabupaten Minahasa Selatan, Jurnal EMBA, Vol.1 No.4, Hal. 1748-1759 
Kara, Muslimin., 2013, Konstribusi Pembiayaan Perbankan Syariah Terhadap Pengembangan Usaha Mikro, Kecil, Dan Menengah, Ahkam, Vol. XIII, No. 2.

Limi, Muhammad Aswar Limi, La Sara, Taane La Ola, Lukman Yunu, (2017), Environmental Changes and Fisherman Welfare in Coastal Area of Kendari Bay, Agriculture, Forestry and Fisheries 2017; 6(1): 20-25

Ledgerwood, Joanna. (2013). The New Microfinance Handbook: A Financial Market System Perspective. Word Bank: Washington D.C

Lukkaa, K., dan S. Modell, 2010. Validation in Interpretive Management Accounting Research. Accounting, Organizations and Society, 35: 462477.

Lubis, Ernani, Anwar Bey Pane, Retno Muninggar, dan Asep Hamzah. 2012, Besaran Kerugian Nelayan dalam Pemasaran Hasil Tangkapan : Kasus Pelabuhan Perikanan Nusantara Palabuhan Ratu, Maspari Journal, 2012, 4 (2), 159-167

Muhammad (2002), Manajemen Pembiayaan Bank Syariah, (Yogyakarta: UPP. AMN YKPN, 2002), h. 17

Marshall, Martin N. (1996). Sampling for Qualitative Research. Family Practice, An International Journal. Vol 13, No 6. Oxford University Press.

Mulyadi. (2005). Ekonomi Kelautan. Jakarta: PT. Raja Grafindo Persada

Mubyanto, dkk. (1984). Nelayan dan Kemiskinan. Jakarta : Rajawali Press.

Moleong, Lexy J, (1996), Metodologi Penelitian Kualitatif, Remaja Rosdakarya: Bandung

Marbun, Leonardo \& Ika N. Krishnayanti. 2002. Masyarakat Pinggiran Yang Kian Terlupakan. Medan : Jala Konpalindo.

Mira, Rukmana (2016) Alasan Masyarakat Nelayan Tidak Mengambil Kredit Usaha Rakyat (Kur) (Studi Kasus:Masyarakat Nelayan Kampung Batu, Kelurahan Batang Arau Kecamatan Padang Selatan, Kota Padang. Thesis, Universitas Andalas.

Nugroho, Lucky dan Dewi Tamala, 2018, Persepsi Pengusaha Umkm Terhadap Peran Bank Syariah, SIKAP, Vol 3 (No 1), 49-62

Nasikun, (1993), Sistem Sosial Indonesia, PT. Raja Grafindo Persada: Jakarta.
Nugroho, A.E. (2017). Politik Ekonomi Kredit Program Untuk Pemberdayaan Usaha MikroKecil: Dari Bimas Hingga Kredit Usaha Rakyat, Bab 5 Dalam Buku, Saptia, Yeni dan Nugroho, A.E., (eds), 2017, Penguatan Peran Program Kredit Mikro Dalam Mendorong Pengembangan UMKM Di Sektor Pertanian, Jakarta: LIPI-Press.

Ogboi, Charles. (2013). Impact of Credit Risk Management on the Financial Performance of Commercial Banks in Nigeria. Journal of Emerging Issues in Economics, Finance Banking (JEIEFB) An Online International Monthly Journal.

Prabawa, S. (1998). Sumberdaya Keluarga dan Tingkat Kesejahteraan Rumah Tangga Petani (Studi di Desa Wates Jaya, Kecamatan Cijeruk, Kabupaten Bogor, Propinsi Jawa Barat. Tesis (tidak diterbitkan). Fakultas pertanian, Institut Pertanian Bogor.

Peraturan Menteri Kelautan Dan Perikanan Republik Indonesia Nomor:

Per.18/Men/2012TentangPedoman Penyusunan Rencana Induk PengembanganKawasan Minapolitan

Putri, Hesty Ristiani dan Sardjito, (2016), Arahan Pengembangan Kawasan Prigi Kecamatan Watulimo Kabupaten Sidoarjo Melalui Konsep Minapolitan, JURNAL TEKNIK ITS Vol. 5, No. 2, (2016) ISSN: 2337-3539 (2301-9271 Print)

Rambe, Armaini. (2011). Alokasi Pengeluaran Rumah Tangga dan Tingkat Kesejahteraan (Kasus di Kecamatan Medan Kota, Sumatera Utara). Tesis (tidak diterbitkan). Medan Universitas Sumatera Utara

Rusliadi, Iskandar Putra, Muhammad Fauzi, Niken Ayu Pamukas, Heri Masjudi 2018. Pengembangan mata pencaharian alternatif bagi nelayan melalui kegiatan budidaya ikan dengan teknologi bioflok di Kampung Sungai Kayu Ara, Riau Journal of Empowerment, Vol 1 (2): 61-65

Sitinjak, Ladestam dan Henry Sinaga. 2019, Strategi Pemberdayaan Masyarakat Nelayan Untuk Meningkatkan Kesejahteraannya Di Kelurahan Sibolga Ilir Kecamatan Sibolga Utara Kota Sibolga, Jurnal Penelitian Terapan Perikanan dan Kelautan, Vol 11., No 1

Senton, Andrew K. (2004). Strategies For Ensuring Trustworthiness in Qualitative Research Project. Education For Information. 22. 63 -75 
Strauss, Anselm., dan Juliet Corbin. 2003. DasarDasar Penelitian Kualitatif. Penerbit Pustaka Pelajar. Yogyakarta

Sanjaya, I.M dan Nursechafia. (2016). Inklusi Keuangan dan Pertumbuhan Inklusif: Analisis Antar Provinsi di Indonesia. Buletin Ekonomi Moneter dan Perbankan, Volume 18, Nomor 3, Januari 2016

Suyoto, Agustinus. (2004). Konsep keluarga reatif ebagai Alternatif Perwujudan Keluarga Yang Sejahtera Dan Mandiri Di Era Globalisasi.Esai/Artikel Pemenang Harapan II Lomba Karya Tulis Keluarga Nasional XI 2004. BKKBN Wilayah DIY

Sugiharto, Eko. (2007), Tingkat Kesejahteraan Masyarakat Nelayan Desa Benua Baru Ilir Berdasarkan Indikator Badan Pusat Statistik, EPP, Vol.4., No.2., 32-36

Suyanto Igit, (2009), Studi Implementasi Program Pemberdayaan Masyarakat Pesisi (PEPM) Studi Kasusu Masyarakat Pesisir Kelurahan Tanjung Emas,

Sugiyono,(2008), Metode Penelitian Kuantitatif, Kualitatif dan $R \& D$, Penerbit Alfabeta, Bandung

Rostin. (2016). The Effect of Economic Empowerment of the Coastal Communities and Social Capital on Coastal Community Welfare. The International Journal of Engineering And Sciences (IJES) Vol. 5 Issue 2.

Rahim, A. (2018). The Empowerment Strategy of The Traditional Fisherman's Wives in The Coastal Area of Barru Regencey, South Sulawesi. Journal of Socioeconomics and Development Vol. 1 No. 12018.
Triyanti, R. dan Firdaus, M. (2016). Tingkat Kesejahteraan Nelayan Skala Kecil Dengan Pendekatan Penghidupan Berkelanjutan di Kabupaten Indramayu. Jurnal Sosial Ekonomi Kelautan Perikanan,Vol. 11 No. 12016

Takariani, C.S.D. (2015). Opini Nelayan Tentang Akses Informasi Publik. Jurnal Penelitian dan Komunikasi, Vol. 18 No. 2 Desember 2015.

Tjahjono, Agoes Boedi, Silfiati, Rini Idealialily, Munari Kustanto, Fitriyatus Sholih, Munari Kustanto 2018, Data Dinamis Kabuaten Sidoarjo, Badan Perencanaan Pembangunan Daerah Pemerintah Kabupaten Sidoarjo

Ulfa, Maria. 2017. Persepsi Masyarakat Nelayan Dalam Menghadapi Perubahan Iklim (Ditinjau Dalam Aspek Sosial Ekonomi), Jurnal Pendidikan Geografi: Kajian, Teori, dan Praktik dalam Bidang Pendidikan dan Ilmu Geografi Tahun 23, Nomor 1, Jan 2018 Halaman: 41-49

Wahid, Nusron. (2014). Keuangan Inklusif, Membongkar Hegemoni Keuangan; Peran Kredit Usaha Rakyat Dalam Menurunkan Kemiskinan dan Pengangguran. KPG Bekerjasama dengan Inter Café IPB dan OJK, Jakarta

Yaskun, Mohammad dan Edie Sugiarto. 2017. Potensi Hasil Perikanan Laut Terhadap Kesejahteraan Para Nelayan Dan Masyarakat Di Kabupaten Lamongan, Jurnal Studi Manajemen Dan Bisnis, Vol. 4 No. 1 